\title{
O OlHar das CiênCIAS SOCIAIS brasileiras Sobre o Supremo Tribunal FEDERAL: UMA BREVE REVISÃO BIBLIOGRÁFICA DOS ESTUdOS PRODUZIDOS SOBRE O STF
}

\author{
The social sciences approach in relation to Brazilian Supreme Court: a \\ bibliographic essay about research produced.
}

IZABEL NuÑez

Bacharel em Direito pela PUCRS, Mestre em Sociologia e Direito pela UFF. Pesquisadora do Centro de Justiça e Sociedade (CJUS) da Escola de Direito da Fundação Getulio Vargas (FGV Direito Rio) no Rio de Janeiro e do Instituto Nacional de Estudos Comparados em Administração Institucional de Conflitos (INCT-InEAC). Na FGV Direito Rio integra a equipe do Projeto "O Supremo por seus ministros: a história oral do STF nos 25 anos da Constituição (1988-2013)" como Assistente de Pesquisa. E-mail: izabelsn@gmail.com.

\section{Thiago Filippo}

Graduando em Direito pela Escola de Direito da Fundação Getulio Vargas (FGV Direito Rio) no Rio de Janeiro e Bolsista de Iniciação Científica no Projeto "O Supremo por seus ministros: a história oral do STF nos 25 anos da Constituição (1988-2013)’.E-mail: thiagofilippo@gmail.com.

RECEBIDO EM: 03.09.2012

APROVADO EM: 04.01.2013

\section{RESUMO}

A presente pesquisa, inserida no contexto de um projeto de pesquisa mais amplo, propõe fazer uma revisão bibliográfica preliminar dos trabalhos realizados no campo das ciências sociais, especialmente na ciência política e na sociologia, sobre o Supremo Tribunal Federal (STF). Por meio do levantamento de pesquisas apresentadas nos $22^{\circ}$ a $35^{\circ}$ encontros anuais da Associação Nacional de Pós-Graduação e Pesquisa em Ciências Sociais (ANPOCS) e, também, da busca de trabalhos disponíveis no Scientific Electronic Library Online (Scielo), apresentamos aqui uma descrição preliminar das pesquisas encontradas que têm como objeto o Supremo Tribunal Federal a partir de diferentes abordagens metodológicas e teóricas. 
Palavras-chave: Revisão bibliográfica. Supremo Tribunal Federal. ANPOCS. SCIELO.

\begin{abstract}
This paper intends to produce a preliminary bibliographic essay about research produced inside Brazilian social sciences, specially inside political science and sociology studies which are focused on the Supremo Tribunal Federal - STF which is the Brazilian Supreme Court. The data presented here was collected from two different sources: both Associação Nacional de Pós-Graduação e Pesquisa em Ciências Sociais (ANPOCS) Annual Meetings and also from Scientific Electronic Library Online (Scielo) database. So, here we present the works we found, that are focused on STF. For those, we present different themes we could see and different methodological and theoretical approaches we were able to diagnose.
\end{abstract}

Keywords: Bibliographic essay. Supremo Tribunal Federal. ANPOCS. Scielo.

Sumário: Introdução. 1. Anpocs: breve revisão bibliográfica dos trabalhos encontrados. 1.1 O Supremo Tribunal Federal e o Controle de Constitucionalidade. 1.2 Judicialização da Política ou Politização da Justiça. 1.3. O Supremo Tribunal Federal como cúpula do Poder Judiciário. 1.4. Análises que enfocam o perfil dos Ministros do STF. 1.5. Processo Decisório dos Ministros do Supremo Tribunal Federal. 2. Scielo: breve revisão bibliográfica dos trabalhos encontrados. 2.1. O Supremo Tribunal Federal e o Controle de Constitucionalidade. 2.2 Judicialização da Política ou Politização da Justiça. 2.3. Processo Decisório dos Ministros do Supremo Tribunal Federal. 2.4. Atuação do Supremo Tribunal Federal. Conclusão. Referências.

\title{
INTRODUÇão
}

O presente trabalho consiste em levantamento preliminar realizado no âmbito de um projeto de pesquisa mais amplo, desenvolvido pela FGV Direito Rio, em conjunto com a Direito GV (São Paulo) e o Centro de Pesquisa e Documentação de História Contemporânea do Brasil (CPDOC), intitulado "O Supremo por seus ministros: a história oral do STF nos 25 anos da Constituição (1988-2013)". O referido projeto, utilizando o método-fonte-técnica da história oral, pretende reconstruir e reinterpretar a história recente do Supremo Tribunal Federal a partir da realização de entrevistas com os magistrados que integraram a Corte nestes últimos 25 anos. Para 
tanto, antes da elaboração dos roteiros de entrevistas e da realização dessas, foram desenvolvidos estudos preliminares de levantamento e pesquisa de temas correlatos ao objeto pesquisado: o Supremo Tribunal Federal. Nesse contexto, a pesquisa que aqui apresentamos traz uma breve revisão bibliográfica após o mapeamento de alguns estudos existentes no campo das ciências sociais no Brasil sobre o STF. Para pensarmos o formato do presente trabalho consultamos levantamentos bibliográficos realizados em diferentes áreas, sobre diferentes objetos de pesquisa (Oliveira, 2012; Kant de Lima, Misse e Mendes de Miranda, 2000; Sadek, 2002; Valladares e Medeiros, 2003).

Assim, para o levantamento a que nos propusemos, primeiro investigamos os espaços nos quais o conhecimento produzido dentro das ciências sociais é compartilhado ${ }^{355} \mathrm{e}$, aqui, trazemos uma análise descritiva das pesquisas apresentadas nos encontros anuais da Associação Nacional de Pós-Graduação e Pesquisa em Ciências Sociais (ANPOCS). Além disso, apresentamos os artigos disponíveis na base de dados da Scientific Electronic Library Online (Scielo). Os artigos do Scielo foram pesquisados de forma a identificar outros trabalhos além daqueles apresentados nos encontros da ANPOCS e, dessa forma, complementar o levantamento inicial.

Todos os trabalhos foram agrupados por temas, ou seja, de acordo com as abordagens semelhantes, sobre o STF. Na primeira e na segunda parte do artigo, faremos uma breve análise do conteúdo de cada um dos trabalhos encontrados. Os temas que identificamos foram ${ }^{356}:$ 1) Judicialização da Política ou Politização da Justiça: trabalhos que tratam da relação entre os três poderes e abordam a atuação do Supremo Tribunal Federal como órgão político ${ }^{357}$. 2) Perfil dos Ministros: artigos que tratam da carreira dos ministros, perfil biográfico ou de suas relações sociais e institucionais. 3) Atuação do STF: pesquisas nas quais a atuação do Supremo é tratada de forma mais ampla, como nos julgamentos de Mandados de Injunção; 4) Controle de Constitucionalidade: trabalhos que tratam exclusivamente dessa competência do STF; 5) Judiciário - STF órgão de cúpula: pesquisas que focam no funcionamento do poder judiciário, ou na reforma do judiciário e mencionam o STF por ser órgão

355 Os principais encontros das Ciências Sociais que acontecem no Brasil são, além da ANPOCS, os encontros da Associação Brasileira de Ciência Política (ABCP); encontros da Sociedade Brasileira de Sociologia (SBS) e os encontros da Associação Brasileira de Antropologia (ABA). Como a produção sobre o Supremo tem se dado majoritariamente nas disciplinas da Ciência Política e da Sociologia, embora tenhamos conhecimento de duas teses defendidas em um Programa de Pós Graduação em Direito, sob orientação de um antropólogo, neste momento da pesquisa optamos por focar no encontro da ANPOCS, porque já havia um levantamento prévio.

356 Cientes de que toda classificação é arbitrária, buscamos partir da abordagem dos próprios autores, de modo a agrupar os temas partindo das categorias presentes nos textos.

357 Importante destacar que foram excluídos de nossa análise trabalhos sobre a Judicialização da Política que tratavam da atuação de outros órgãos do Judiciário, como por exemplo, o Ministério Público. 
de cúpula do referido Poder; e 6) Processo Decisório: artigos que pesquisam como os ministros do Supremo produzem as suas decisões.

Dessa forma, passamos a apontar as pesquisas localizadas e relatar as correlações que encontramos entre as produções. Num primeiro momento, trazemos as pesquisas apresentadas na ANPOCS. Na segunda parte do artigo descrevemos os resultados encontrados no Scielo e, por fim, traçamos algumas conclusões sobre o olhar das ciências sociais em relação ao STF, assim como sobre a relevância do presente trabalho para nosso projeto de pesquisa. Após as referências bibliográficas, listamos as referências das fontes de pesquisa que são, elas mesmas, os trabalhos que consultamos para a elaboração do presente artigo, isto é, os trabalhos a partir dos quais realizamos o presente levantamento bibliográfico.

\section{ANPOCS: BREVE REVISÃO BIBLIOGRÁFICA DOS TRABALHOS ENCONTRADOS}

Em relação aos trabalhos apresentados nos encontros da ANPOCS, partimos do levantamento que já havia sido feito para o projeto Mais Justiça e Socieda$\mathrm{de}^{358}$, desenvolvido pela FGV Direito Rio, e inserimos outros termos de pesquisa. A coleta teve como referência os anais do $22^{\circ}$ ao $35^{\circ}$ Encontro Anual, cobrindo treze encontros no período que vai de 1998 a $2011^{359}$.

Como muitos dos temas anteriormente aplicados como chave de busca não nos interessavam, realizamos a filtragem desses termos, ficando somente com os termos "judicialização" e "Supremo Tribunal Federal/STF". Inserimos, ainda, o termo "ministros" no intuito de mapearmos trabalhos sobre o perfil dos magistrados da Corte.

Após a primeira filtragem descrita, chegamos a 34 artigos. Desses, excluímos aqueles que versavam sobre judicialização ou judiciário, mas que não tratavam do Supremo Tribunal Federal. Chegamos, então, ao número de 16 trabalhos $^{360}$.

Abaixo, apresentamos um gráfico contendo a relação entre os temas mais

358 Partimos, então, do levantamento já feito em pesquisa desenvolvida no CJUS, no âmbito do Projeto Mais Justiça e Sociedade, sob a coordenação da Professora Fabiana Luci Oliveira e cujos resultados estão publicados no livro "Justiça em Foco" (Oliveira, 2012).

359 Os termos de pesquisa utilizados no levantamento realizado para o projeto mais Justiça e Sociedade, isto é, que não contemplavam o ano de 2011, foram: 1. Justiça; 2. Tribunal; 3. Judiciário; 4. Judicial; 5. Juiz/Juízes; 6. Judicialização; 7. Direito; 8. Supremo Tribunal Federal/ STF; 9. Ministério Público; 10. Defensoria; e 11. Superior Tribunal de Justiça. Assim, para a presente pesquisa, reaplicamos o filtro com o termo Ministros nos encontros realizados entre os anos de 1998 e 2010 e, ainda, consultamos os trabalhos apresentados no 35o encontro aplicando, a esse, todos os termos de pesquisa. Nossa coleta foi, portanto, ampliada, sendo inseridos mais quatro trabalhos apresentados sobre o tema no ano de 2011.

360 Destacamos que três trabalhos foram excluídos de nossa pesquisa porque os respectivos textos não foram encontrados e, assim, não foi possível precisar somente a partir da análise dos títulos, se o objeto das pesquisas relacionava-se, ou não, com o STF. 
recorrentes e a quantidade de trabalhos apresentados sobre cada tema. Assim, conforme se pode ver no gráfico abaixo, nos encontros da ANPOCS, os temas mais recorrentes foram: processo decisório (cinco trabalhos), judicialização da política (quatro trabalhos) e perfil biográfico dos ministros e controle de constitucionalidade (três trabalhos cada). O tema menos recorrente, foi judiciário.

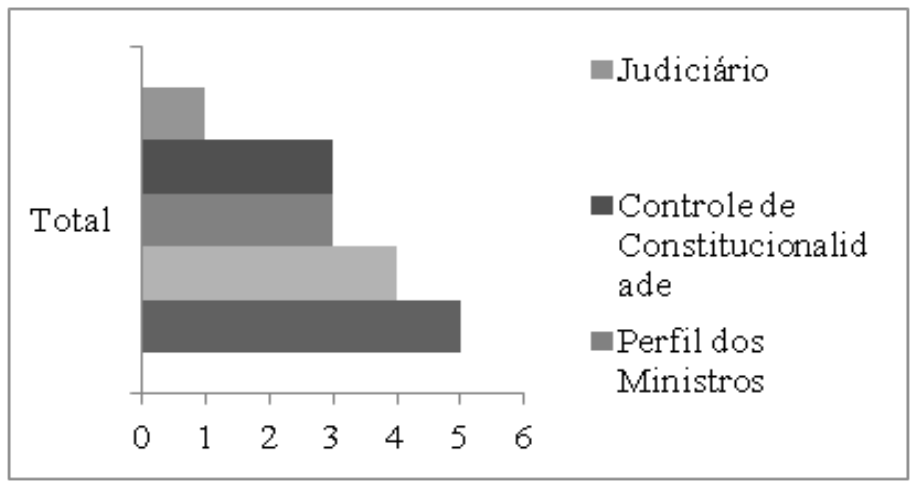

Gráfico 1 - Temas mais recorrentes nos encontros da ANPOCS

Sobre a relação entre trabalhos publicados por ano, apresentamos o gráfico abaixo. Quanto aos trabalhos sobre o Supremo Tribunal Federal, produzidos entre 1999 e 2005, foi apresentado um trabalho por ano. De 2006 a 2010, houve a apresentação de dois trabalhos por ano, e em 2011, quatro pesquisas tinham a Suprema Corte como objeto. Notamos, portanto, que houve um aumento gradual na quantidade de trabalhos produzidos sobre o tema. Já no ano de 2011 foram apresentados quatro trabalhos que tinham como objeto o Supremo Tribunal Federal.

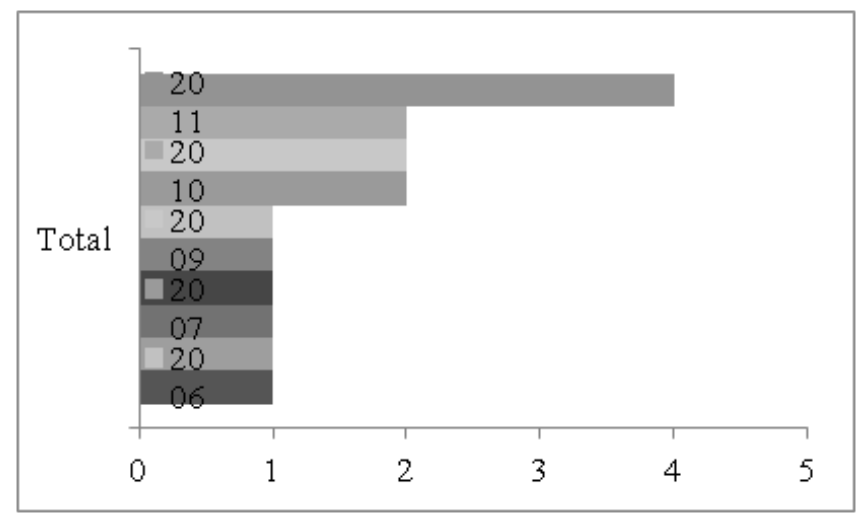

Gráfico 2 - Trabalhos sobre o STF apresentados por ano 
Podemos destacar, ainda, que doze dos dezesseis trabalhos localizados foram produzidos a partir da realização de pesquisa empírica. A maioria das pesquisas que apresentavam algum tipo de abordagem empírica partia da organização de um banco de dados por meio das informações contidas em Ações Diretas de Inconstitucionalidade (ADIns). Nesse sentido, temos os trabalhos de Pacheco, 2005; Koerner, Baratto e Inatomi, 2007; Werneck Vianna, 1999; Mariano Silva, 2010; e Araujo, 2011.

Além disso, outros trabalhos realizavam análise de processos judiciais ou decisões proferidas pelo STF (Costa Júnior, 2006; Zaulli, 2010; Lewandowski, 2011 e Iorio Filho e Silva, 2011). Apenas um trabalho (Cunha Filho, 2011) fazia a análise a partir de decisões proferidas em Mandados de Injunção. Destacamos, ainda, as pesquisas de Oliveira, 2002 e Santos e Da Ros, 2007 que, por meio de material empírico relacionado ao currículo e à biografia dos ministros, analisaram a existência de mudanças significativas no perfil dos magistrados que passaram a integrar a Corte e o impacto, correspondente à essas mudanças de perfil, no funcionamento do STF.

\subsection{O Supremo Tribunal Federal e o Controle de Constitucionalidade}

Sobre o tema de Controle de Constitucionalidade, foram localizados três trabalhos. O primeiro deles, apresentado no ano de 2003, analisa comparativamente os modelos de controle constitucional dos atos do Executivo adotados no Brasil e na Argentina. Depois, discute o comportamento dos Executivos desses países quanto ao uso de Medidas Provisórias (MPs) e Decretos de Necessidade e Urgência (DNUs) nos respectivos países. E, por fim, verifica como seus Judiciários decidiram quando provocados a declarar (in)constitucionalidade dos pressupostos que autorizam a edição de MPs e de DNUs. Trata-se de um trabalho teórico (Marchetti, Vitor, 2003).

O segundo trabalho encontrado, já produzido no ano de 2005, foi realizado a partir da construção de um banco de dados contendo informações de 513 ADINs julgadas entre os anos de 1995 e 1998. Na análise da autora, dois pontos chamam atenção: (1) a atuação do STF tem sido a da "não decisão sistemática", através do proferimento de sentenças que, em sua maioria, são arquivadas por motivos processuais, sem que haja, portanto, julgamento do mérito. A taxa de decisão de mérito da Corte é de 30\%. E, também, (2) a atuação do Supremo durante o primeiro mandato de Fernando Henrique foi de apoio à implementação das reformas (Pacheco, 2005).

$\mathrm{O}$ terceiro trabalho consiste em pesquisa que teve por objetivo a caracterização das "formas de racionalidade jurídica" presentes nas decisões dos ministros, no contexto institucional do STF e sob condições políticas determinadas, a partir de conceitos jurídicos elaborados pelos ministros nos seus votos e argumentos nas Ações Diretas de Inconstitucionalidade (ADINs). Para tanto, os pesquisadores criaram um banco de dados, por meio das informações disponíveis no site do Supremo, 
com decisões proferidas no período de 1988 a 1999. Os autores procuram realizar uma análise capaz de identificar quais são as decisões mais relevantes nesse. Assim, a relevância foi definida por eles como presente nas decisões nas quais o exame do conceito jurídico pelo Tribunal foi suficientemente detido a ponto de provocar uma modificação expressa daquele conceito, se comparado a decisões anteriores. (Koerner, Baratto e Inatomi, 2007).

\subsection{Judicialização da Política ou Politização da Justiça}

Sobre o referido tema foram mapeados quatro trabalhos. O primeiro deles, amplamente conhecido tanto no campo do direito quanto nas ciências sociais, tratase de pesquisa desenvolvida pelo professor Luiz Werneck Vianna. A pesquisa analisa o perfil dos conflitos encaminhados às instituições judiciais por meio das Ações Diretas de Inconstitucionalidade: sua distribuição, partes, motivação, origem do diploma legal contestado, categorias dos direitos envolvidos e classe temática das normas questionadas, âmbito de aplicação, entre outras verificações, por meio da análise de uma amostra de 1.935 ADINs ajuizadas no período de 1988 (ano da promulgação da Carta constitucional) e 1998 (Werneck Vianna, 1999).

Passados sete anos encontramos, em 2006, pesquisa que busca compreender a atuação do judiciário nos casos que envolvem agências reguladoras. Para tanto, ao dialogar com teorias neoinstitucionalistas, o autor analisa julgados realizados pelo STF e, ainda, 41 processos judiciais movidos contra concessionárias de serviços públicos, em tramitação na Justiça Federal do Distrito Federal. Como conclusões a pesquisa aponta que: (1) quanto mais alta a posição ocupada por um juiz dentro da hierarquia judicial, maior a probabilidade de a sua decisão, nas políticas regulatórias, atender ao principio da segurança jurídica em detrimento do sistema de defesa do consumidor; e, também (2) há uma conexão entre as decisões do judiciário e o Governo, sobretudo no início da década de 90, com as privatizações (Costa Júnior, 2006).

Posteriormente, no ano de 2010, localizamos o trabalho de Jeferson Mariano da Silva que tem como problema de pesquisa o modo pelo qual o empresariado utiliza a proposição de Ações Diretas de Inconstitucionalidade, de forma a alterar o ordenamento jurídico brasileiro. Para tanto, o autor analisa todas as ADINs que chegaram ao STF até o final do ano 2000, totalizando 2377 ações propostas por entidades empresariais, associações e partidos políticos. Em cada uma delas, foram considerados: a data de distribuição dentro do STF, o requerente, o requerido, o resultado do pedido liminar, a data da decisão do pedido liminar, o resultado da decisão final e a data da decisão final.

Feita uma análise quantitativa e qualitativa das decisões, o autor conclui que as entidades empresariais utilizam as ADINs como "elites na representação junto ao STF" em razão de dois fatores que se reforçam mutuamente: (1) pela obstinação 
dessas organizações em afirmar sua legitimidade como intérpretes da Constituição e representantes legítimas da classe empresarial; e, (2) pela disposição do STF em reconhecer-lhe legitimidade ao mesmo tempo em que não reconhece igual estatuto a outras entidades como associações e partidos políticos (Mariano Silva, 2010).

Ainda no ano de 2010, encontramos pesquisa que analisa, de forma qualitativa, as decisões do STF sobre casos em julgamento nas Comissões Parlamentares de Inquérito. Para tanto, o autor dialoga com teorias existentes sobre a separação dos poderes. Após a realização da pesquisa, o autor diz que o significado da abertura do Supremo para as demandas da sociedade, bem como as decisões relacionadas ao funcionamento das CPIs, remetem à noção de "soberania complexa" e suas repercussões sobre o exercício da cidadania nas sociedades democráticas contemporâneas. Assim, o autor conclui que "o cidadão que representa contra membro de CPI perante o Supremo Tribunal Federal, participa de um processo de procedimentalização da aplicação do direito que, para além das instituições representativas de cunho eleitoral, permite-lhe fazer-se representado em âmbito judicial em defesa de seus direitos" (Zauli, 2010).

\subsection{O Supremo Tribunal Federal como cúpula do Poder Judiciário}

Sobre o tema "judiciário", isto é, pesquisas que focam no funcionamento do poder judiciário, ou na reforma do judiciário e mencionam o STF por ser órgão de cúpula deste poder, encontramos o trabalho de Ronaldo Porto Macedo e Ana Cristina Braga Martes. A pesquisa dos autores, apresentada no encontro da ANPOCS realizado no ano de 2000, analisa o texto da Emenda Constitucional n. 45/2004, que trouxe a Reforma do Judiciário e foca, entre outros pontos que afetaram o Supremo Tribunal Federal, na criação da súmula vinculante no STF. Não há pesquisa empírica no referido trabalho (Porto Macedo Júnior e Martes, 2000).

\subsection{AnÁlises que enfocam o PERfil dos Ministros do STF}

Em relação ao perfil dos ministros encontramos três pesquisas inscritas nos encontros anuais da ANPOCS. A primeira delas, divulgada no ano de 2002, está inserida na discussão das relações entre profissão e política e tem como argumento principal: "que os ministros transformaram o STF em um ator de suma importância no processo de redemocratização e consolidação da democracia, buscando a expansão de seus poderes políticos sem "politizar" suas funções, sem perder a credibilidade do Supremo como órgão do Judiciário". São quatro as questões discutidas pela autora: o perfil biográfico e a trajetória de carreira dos ministros, a imagem e o discurso públicos da instituição, relacionando-os às mudanças ocorridas nas atribuições constitucionais do STF. Por meio de pesquisa empírica (análise do perfil biográfico dos ministros a partir do conteúdo do discurso público dos ministros, veiculados na 
Revista Forense e também análise de matérias jornalísticas publicadas nos jornais A Folha de São Paulo e O Estado de São Paulo) a autora realiza sua pesquisa (Oliveira, 2002).

No segundo trabalho localizado, apresentado no encontro anual da associação ocorrido em 2007, os autores fazem a análise do Perfil Biográfico e Profissional dos Ministros do Supremo Tribunal de Justiça (STJi) e do Supremo Tribunal Federal. A partir das biografias dos ministros do STJi e do STF, disponíveis no portal eletrônico do órgão, traçaram o perfil dos membros recrutados para tais Cortes e buscaram compreender os padrões de carreira e de recrutamento dos ministros que atuaram nos órgãos de cúpula do poder Judiciário ao longo da história brasileira.

Algumas das principais conclusões apontadas foram: 1) houve uma redução na mobilidade dos ministros, ou seja, antes os ministros migravam mais para estudar e mais contemporaneamente acabam mantendo-se em seus estados de origem. 2) Houve um lento incremento na proporção de ministros nomeados vindos de carreiras profissionais exclusivamente jurídicas, isto é, ao longo dos anos mais magistrados de carreira passaram a integrar os quadros do STF 3) Sobre as carreiras profissionais dos Ministros, durante o Império um em cada dez ministros havia percorrido unicamente profissões jurídicas e $2 / 3$ dos ministros apresentavam experiências políticas de modo que era possível verificar expressiva frequência na sobreposição de carreiras jurídicas e funções políticas (Marenco Dos Santos, Da Ros, 2007).

$\mathrm{O}$ terceiro trabalho trata-se de pesquisa teórica que, a partir da reconstrução do processo de Reforma do Judiciário resultante na aprovação da EC 45/2004, busca realçar a participação de grupos de elites jurídicas na finalização do chamado primeiro ciclo da Reforma (2002-2004). Assim, ao analisar as estruturas, agentes, relações de poder e processos de longo prazo que delimitam o que o autor chama de campo político da justiça - o espaço social de poder associado (mas não limitado) às instituições estatais, organizações profissionais e procedimentos oficiais de resolução de conflitos pelo Poder Judiciário, busca compreender os grupos que participaram da referida reforma.

$\mathrm{O}$ argumento principal do texto acima citado é que a obtenção de consensos mínimos para a aprovação da Reforma do Judiciário deveu-se à articulação, pela liderança executiva da Reforma, de grupos de elites jurídicas associados a trajetórias e posições bastante consolidadas no campo. Para tanto, dialoga com texto de Joaquim Falcão: Estratégias para a Reforma do Judiciário que, segundo o autor, embora atribua o sucesso da Reforma à aliança entre o Ministério da Justiça e o Supremo Tribunal Federal e ao consenso mínimo entre as "forças políticas relevantes", não associa expressamente esse consenso ao conteúdo e aos interesses específicos dessas forças na proposta aprovada (Almeida, 2009). 


\subsection{Processo Decisório dos Ministros do Supremo Tribunal Federal}

Quanto ao processo decisório dos ministros da Corte Suprema, foram localizados cinco trabalhos. Destacamos o incremento de pesquisas sobre o tema nos encontros anuais da ANPOCS, já que no ano de 2009 encontramos uma pesquisa sobre a forma pela qual os ministros proferem suas decisões e, já no ano de 2011 foram quatro os trabalhos encontrados. $\mathrm{O}$ trabalho pioneiro buscou situar o poder judiciário e, também o STF, como um ator com poder de veto das decisões políticas a partir de discussão de literatura.

No referido trabalho, por meio de análise teórica, os autores procuram sistematizar pontos que a literatura sobre o processo decisório negligencia, tais como os fatores "micro", isto é, ao não tomar os atores do Poder Judiciário como atores individuais, somente os considerando em relação à instituição e, também, as concepções normativas sobre os ministros. Apontam, ainda, que a literatura clássica sobre judicialização da política negligencia o poder como aspecto importante dessas relações (Ribeiro, Peixoto, Arguelhes, 2009).

No ano de 2011, então, foram apresentados quatro trabalhos sobre o tema. No primeiro deles, o autor faz uma análise qualitativa de decisões proferidas pelo STF em sede de Mandados de Injunção (MI) para julgar a inconstitucionalidade da omissão do Poder Público ao longo dos últimos vinte anos. Como conclusão da pesquisa apresenta o seguinte resultado: o STF evoluiu de uma atitude de rigorosa passividade quanto ao uso de suas prerrogativas de declarar inconstitucionalidades omissivas para uma postura que claramente admite a participação judicial na elaboração de políticas públicas. O que se percebe é que o Tribunal Constitucional brasileiro tem se mostrado cada vez mais disposto a participar do policy-making nacional. Dialoga, para isso, com pesquisas que focam nas ADINs, sustentando que sua análise é limitada porque abarca somente uma nuance da atuação do STF (Cunha Filho, 2011).

Na segunda pesquisa encontrada, o autor desenvolve uma proposta de análise institucional do Poder Judiciário a partir da Teoria dos veto players apresentada por George Tsebelis. Assim, para testar a hipótese teórica de Tsebelis, de que a Corte constitucional estará absorvida na maioria dos casos e, simultaneamente, identificar em quais casos o STF irá atuar como veto player no sistema político brasileiro o autor realiza análise por meio da sistematização de ADINs julgadas entre 1995 e 2010 (Araújo, 2011).

No terceiro artigo, a autora desenvolve análise qualitativa de decisões proferidas pela Suprema Corte. Isto é, por meio da análise documental dos votos proferidos em dez julgamentos realizados pelo Supremo Tribunal Federal, e observações realizadas nesses julgamentos, além da análise de pronunciamentos dos ministros realizados em eventos jurídicos e entrevistas concedidas a veículos da imprensa nacional, a autora visa busca discutir como os "princípios do direito", assim como as 
doutrinas e o próprio texto normativo, agem nas decisões colegiadas. Além disso, a seu ver, também elementos que estão fora desse campo são trazidos nas decisões analisadas, de forma a dar legitimidade e erudição aos votos proferidos, ao mesmo tempo que reforçam uma noção de autoridade do próprio direito na decisão tomada. (Lewandowski, 2011).

Por fim, o último trabalho localizado no encontro da ANPOCS de 2011 tem como objetivo geral perceber como os discursos dos Ministros da Corte Constitucional brasileira se constroem e como eles se relacionam com o poder na defesa da cidadania. Para tanto, a partir da análise do julgamento da Lei da Ficha Limpa (Lei Complementar 135/2010), os autores se propõe a discutir a relação entre as categorias jurídicas e políticas presentes no texto. Partem da hipótese de que os usos do processo podem permitir à Corte enfrentar ou não essa moderação democrática, definindo os limites do político no jurídico. (Iorio Filho e Silva, 2011).

\section{SCIELO: BREVE REVISÃo BIBLIOGRÁFICA dOS TRABALHOS ENCONTRADOS}

A coleta das pesquisas existentes foi feita em toda a base de periódicos brasileiros disponíveis na página da Scielo. Os termos de busca utilizados foram "Supremo Tribunal Federal", "judicialização", "STF" e "ministro 361 ". Não houve recorte temporal, uma vez que somente trabalhos dos anos de 2004 em diante foram encontrados. Inicialmente foram listados 38 artigos.

Após o levantamento inicial, aplicamos o primeiro filtro, que excluiu, sobretudo, trabalhos que tratavam do tema "judicialização", mas não tinham como objeto o STF. Desta forma, ficamos com vinte artigos, todos oferecendo elementos de análise para compreender-se o objeto de nossa pesquisa, o Supremo Tribunal Federal. Foi possível identificarmos que a fonte principal dos estudos são as decisões proferidas pelos ministros, tanto nas Ações Diretas de Inconstitucionalidade quanto por meio da análise de outros processos e decisões. Os pesquisadores não realizam entrevistas, etnografias ou observações participantes no Supremo Tribunal Federal.

Abaixo, apresentamos a relação entre as publicações e os temas e foi possível perceber que no Scielo os trabalhos que tem como objeto o Supremo Tribunal Federal, em geral, tratam da Judicialização da Política. Foram encontrados dez trabalhos sobre o tema e o ápice de produção se deu no ano de 2008, conforme falaremos adiante. $\mathrm{O}$ segundo tema mais recorrente foi a atuação do Supremo, com quatro trabalhos e, logo em seguida Processo Decisório no STF e Controle de Constitucionalidade com três artigos cada. Por fim, temos o tema da Separação de Poderes com dois trabalhos e Perfil dos Ministros aparece no Scielo somente com uma pesquisa publicada.

361 O termo "ministro" trouxe os mesmos trabalhos que as outras chaves de busca apresentaram, ou seja, foram listados resultados repetidos. 


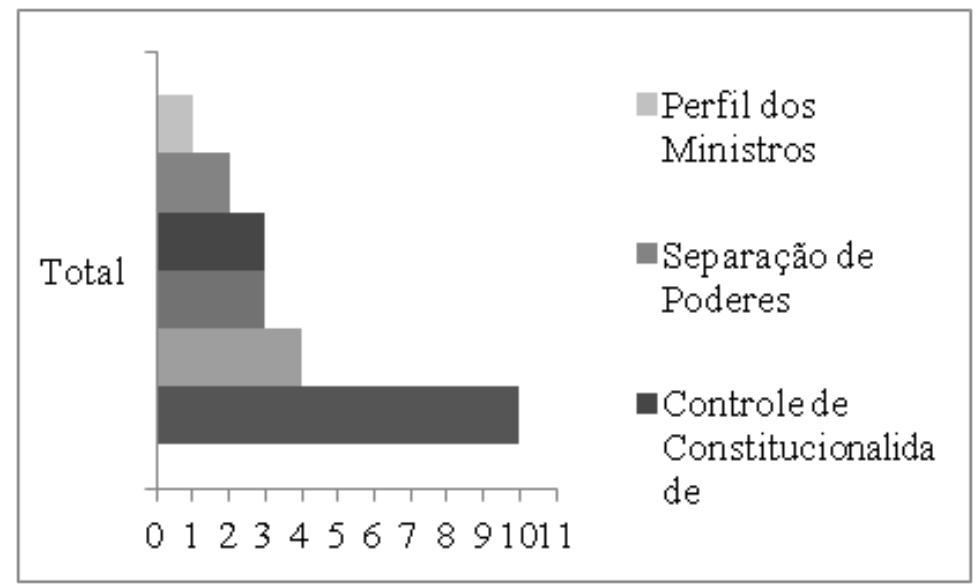

Gráfico 3 - Temas mais recorrentes nos artigos do Scielo

Quanto à relação entre o ano e a quantidade de produções, foi possível identificarmos um aumento significativo das pesquisas a partir do ano de 2008, quando o número de trabalhos publicados salta de um para sete. Em seguida, há uma redução gradual, sendo seis trabalhos acadêmicos publicados sobre o assunto no ano de 2009 e quatro no ano de 2010.

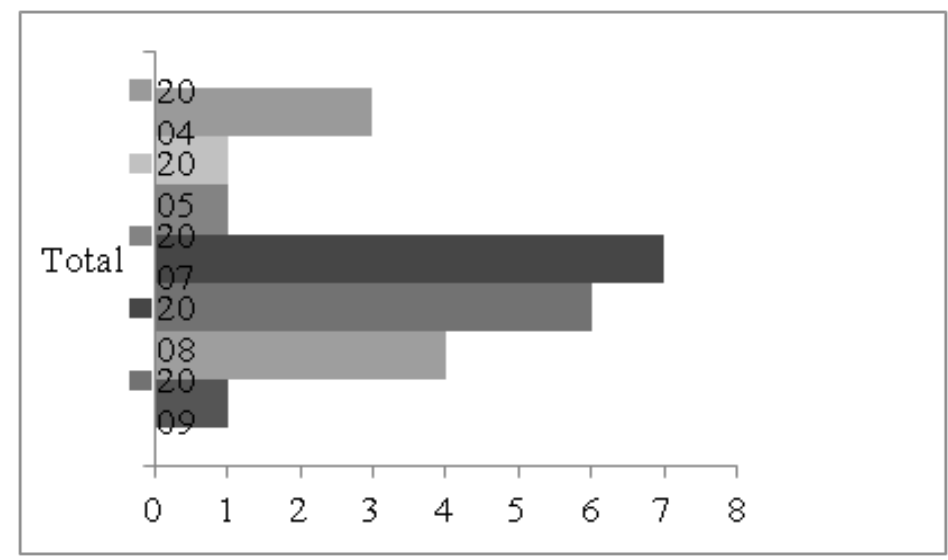

Gráfico 4 - Trabalhos sobre o STF publicados no Scielo por ano

Destacamos, ainda, que dentre os vinte trabalhos identificados, oito consistiam em pesquisas puramente teóricas. Dos doze trabalhos empíricos, quatro que realizaram estudos de caso (Duran-Ferreira, 2009; Zauli, 2011; e Rothenburg, 2009). 
O restante foi elaborado com base na construção de bancos de dados a partir de material contido em decisões proferidas pela Suprema Corte brasileira (Elias de Oliveira, 2005; Werneck Vianna, 2007; Verissimo, 2008; Taylor, 2008; Elias de Oliveira, 2009; Ximenes, 2010; Abramo, 2010; e Wang, 2008).

\subsection{O Supremo Tribunal Federal e o Controle de Constitucionalidade}

Encontramos um artigo na base do Scielo, publicado no ano de 2009. O trabalho analisa as decisões do STF no uso de seu poder de controle de constitucionalidade sobre as agências reguladoras do Sistema Financeiro Nacional. Por meio de análise qualitativa de quatorze ADINS que tratam da regulação do Sistema Financeiro Nacional, a autora chegou à conclusão que, inicialmente, a atuação do STF era apolítica, não julgando o mérito das decisões expedidas pelo legislativo e as autoridades executivas do setor financeiro. A partir do julgamento da constitucionalidade do Código de Defesa do Consumidor, foi observada uma crescente tendência de teor político nas decisões de nossa suprema corte na judicialização da matéria (DuranFerreira, 2009).

\subsection{Judicialização da Política ou Politização da Justiça}

Em relação ao tema da Judicialização da Política, isto é, sobre a atuação do Supremo Tribunal Federal como órgão político, foram localizados dez trabalhos. As pesquisas sobre o tema começam a ser publicadas em 2004 e tem no ano de 2008 a maior produção. Nesse ano foram identificados cinco trabalhos no Scielo. Depois, foi produzido um artigo por ano sobre o tema.

O primeiro trabalho encontrado, escrito por Ernani Rodrigues de Carvalho, discute critérios tradicionais para a definição da judicialização da política no Brasil, compara o desenvolvimento da judicialização da política no Brasil com os argumentos trazidos na coletânea The Global Expansion of Judicial Power, organizada por Neal Tate e T. Vallinder (1995), para tentar alinhar ou não o fenômeno observado no Brasil com os fatores apontados globalmente. Propõe então duas novas abordagens teóricas para o estudo do fenômeno no Brasil: modelo estratégico de comportamento judicial, baseado na análise do comportamento estratégico dos atores nas decisões jurídicas; e o modelo atitudinal, que, pela análise da vida prévia de juízes de cortes supremas, como seria o caso do STF, definir se a atuação dos magistrados está alinhada a determinados posicionamentos ideológicos (Carvalho, 2004).

O segundo trabalho encontrado, consiste em estudo teórico elaborado por Paulo Bonavides. Nele, o autor analisa, por meio da criação de um modelo teórico fundamentado no desenho institucional nacional e na atribuição de competências dos poderes da república, a supremacia do Poder Executivo. Segundo o autor, essa supremacia pode ser caracterizada como "tóxica" ao funcionamento das demais 
instituições. Como solução, sugere o fortalecimento do tribunal constitucional. A hegemonia da administração pública revela-se, na opinião do autor, em medidas como a Ação de Declaração de Constitucionalidade, o que mostra submissão do Legislativo ao permitir que atos como Medidas Provisórias sejam legitimadas pelo tribunal constitucional. Neste sistema, o papel da jurisdição constitucional como legislador negativo tornaria o legislativo ainda mais fraco. Ainda, Bonavides afirma que o modelo de indicação dos Ministros do STF cria uma forte relação entre eles e a Presidência, afetando-lhes a independência (Bonavides, 2004).

No ano de 2005 foi listado um trabalho que discute a judicialização da política a partir da criação de um banco de dados com informações encontradas em ADINs sobre o Plano Nacional de Desestatização. Por meio da análise dos dados por ela levantados, a autora conclui que o judiciário não foi ativo na política de desestatização, não se manifestando sobre o mérito destas políticas mesmo quando provocado a decidir as Adins contrárias ao processo de desestatização. Assim sendo, afirma não haver judicialização da política nesta temática (Elias de Oliveira, 2005).

Publicado em 2007, encontramos o texto de pesquisa coordenada pelo professor Luiz Werneck Vianna. A pesquisa, amplamente conhecida nos campos da ciência política e do direito, faz uma análise qualitativa e quantitativa das decisões, a partir da criação de um banco de dados formado por 3.648 Adins, ajuizadas entre 1988 e 2005. Por meio disso, os autores estudam o funcionamento de Adins tanto como instrumento político de proteção de minorias quanto como instrumento estratégico dos governos (Werneck Vianna, Burgos e Salles, 2007).

No ano de 2008, então, encontramos o ápice da produção sobre a Judicialização da Política. A pesquisa de Loiane Prado Verbicaro busca demonstrar como a abertura do poder judiciário às questões políticas tornou-se um importante instrumento de participação popular nos sistemas decisórios republicanos. Para tanto, trabalha com a recontextualização de teoria social da judicialização da política para o cenário brasileiro, com auxílio da bibliografia nacional acerca do tema. Não há pesquisa empírica em seu trabalho (Verbicaro, Loiane Prado, 2008).

O trabalho desenvolvido por Luciano da Ros tem como objeto o "controle horizontal" (horizontal accountability) do STF quanto ao poder de decreto do Presidente brasileiro. Dialoga com estudos realizados em Ciência Política brasileira, de natureza tanto quantitativa quanto qualitativa, para mostrar como a interferência dos demais poderes irá definir o poder exercido pelo presidente da República em seus dois instrumentos de agenda política principais: decretos e medidas provisórias. O resultado deste estudo é a observação que a atuação dos demais poderes da república não é obstáculo forte ao exercício de poder pelo executivo (Da Ros, 2008).

O terceiro trabalho localizado, publicado no ano de 2008, descreve a mudança de caráter institucional do STF depois da Constituição de 1988, em que tanto se tornou um tribunal com incrementado papel político quanto sobrecarregado em seu volume de trabalho. $\mathrm{O}$ autor analisa dados que compõem as estatísticas de julga- 
mento do Supremo para demonstrar um comportamento ativista do STF a partir do desenho institucional dado ao tribunal em 1988 e na reforma judiciária, que permitiram o aumento de escopo e profundidade da atividade da suprema corte. O autor utiliza banco de dados disponível na página do Supremo e, a partir de tais informações discute o perfil decisório do Tribunal em Adins, assim como o total de processos distribuídos e o aumento de volume anual, total de agravos recebidos, entre outros dados empíricos (Veríssimo, 2008).

A pesquisa de Matthew Taylor, também publicada no ano de 2008, busca destacar as diferenças entre a relação dos presidentes FHC e Lula com a corte constitucional brasileira, comparando os objetivos políticos desenvolvidos pelos dois governos no uso das ADINS. Ou seja, o autor busca estabelecer qual foi o papel de cada presidente no desenvolvimento da judicialização da política. Analisa, para tanto, o uso que cada um dos presidentes fez das Adins e conclui que a judicialização promovida pela política foi quantitativa e substancialmente diferente nos governos FHC e Lula, sem motivos institucionais que justifiquem tal mudança. Assim sendo, o estudo conseguiu descrever três "usos da judicialização": (1) Tática da oposição; (2) arbitragem de interesses em conflito; (3) instrumento de governo (Taylor, 2008).

Ainda, o quinto trabalho sobre o tema publicado no ano de 2008, trata-se de pesquisa de Oscar Vilhena Vieira. A partir da constatação da existência de um projeto constitucional ambicioso, que, além de expandir a matéria constitucional, ampliou as funções do Supremo Tribunal Federal e o rol dos legitimados a questionar a constitucionalidade, o autor aponta uma atuação política exacerbada do STF. Segundo o trabalho do autor, um dos efeitos mais extremos depreendidos do modelo teórico criado é a atuação do tribunal como uma segunda arena política, onde os derrotados políticos questionam a decisão vencedora. Nesse sentindo, cunha o termo "Supremocracia", categoria que aponta para uma hiperatividade do STF (Vilhena Vieira, 2008).

No ano de 2009, foi publicado mais um trabalho, no qual a autora analisa a atuação do Supremo Tribunal Federal em conflitos entre Estados e União. Por meio de pesquisa empírica consistente em análise quantitativa de ADINs no período de 1988 a 2002, a autora chega à conclusão de que há uma tendência do Supremo Tribunal no sentido de julgar a favor da União, seja ela ré ou autora dos processos (Elias de Oliveira, 2009).

Posteriormente, no ano de 2010, foi publicada pesquisa de Ernani Carva1ho. Trata-se de estudo que tem por objetivo localizar fatores de "potencialização" da judicialização da política. Para tanto, o autor analisa a evolução histórica da corte constitucional desde a sua criação até o momento atual no que se refere ao poder de revisão constitucional, verificando um aumento de poder do Executivo, que, segundo ele, usou estrategicamente o poder do tribunal. $\mathrm{O}$ autor observa que, apesar desta influência histórica, hoje o STF é fonte de poder autônomo e influente em questões de relevo nacional, não mais somente por sua competência de controle de constitu- 
cionalidade (Carvalho, 2010).

Ainda em 2010 encontramos artigo que critica a categorização do Supremo como um tribunal constitucional propriamente dito, por meio da construção de um modelo histórico-teórico, da análise de ADINS e dos dados de movimentação processual do STF. A autora conclui que, apesar de sua função de guarda dos valores constitucionais, por instrumentos como o amicus curiae, o STF está aberto a ouvir as demandas populares, tornando-se um ambiente legítimo para a formação da vontade democrática participativa (Ximenes, 2010).

O último trabalho sobre a judicialização da política encontrado no Scielo consiste em artigo que tem por objetivo demonstrar uma avançada judicialização da política pela delimitação do alcance e poderes das CPIs. Para tanto, o autor utiliza de análise jurisprudencial dos casos que tratam do estatuto e limitações constitucionais do trabalho das CPIs (Zauli, 2011).

\subsection{Processo Decisório dos Ministros do Supremo Tribunal Federal}

Localizamos, no Scielo, três trabalhos sobre a forma como os ministros do Supremo produzem as suas decisões. O primeiro deles, publicado em 2009, procura realizar uma análise jurisprudencial à luz da teoria de Ronald Dworkin, de modo a permitir a observação da falta de "unicidade racional" decisória entre os ministros do STF. Assim sendo, de acordo com as autoras, a formulação de decisões do STF não é produzida de forma democrática. Afirmam isso tanto porque compreendem que os ministros representam interesses políticos sem terem sido eleitos, quanto porque, segundo elas, não satisfazem a necessidade de segurança jurídica, função precípua do judiciário no desenho institucional tripartite (Vojvodic, Machado e Cardoso 2009).

Ainda no ano de 2009, localizamos artigo que também ao dialogar com as teorias de Ronald Dworkin, critica a estrutura decisória no processo judicial brasileiro estabelecida pela multiplicidade de influências de tradições e modelos jurídicos. Conjugando a ideia de um modelo híbrido aos argumentos para uso de fundamentação política em decisões judiciais do referido autor, os pesquisadores concluem que o uso de argumentos políticos no STF é exacerbado, de forma que este está usurpando competências do legislativo e executivo, uma vez que o processo decisório não é nem uniforme nem transparente (Chueiri e Sampaio, 2009).

Ainda, localizamos estudo publicado em 2010, que busca a construção de critérios objetivos de avaliação do desempenho de cada magistrado em relação ao "objetivo da justiça". O método proposto pelo autor consiste na criação de modelos matemáticos objetiváveis em relação a cada tipo processual em trâmite no STF, de forma a calcular o tempo de espera no julgamento de casos no Supremo. O método busca evitar que argumentos relacionados à natureza de diferentes processos afetem o tempo de seus julgamentos. (Abramo, 2010). 


\subsection{Atuação do Supremo Tribunal Federal}

Nessa categoria agrupamos os estudos que buscam compreender a atuação do Supremo, não especificamente o processo decisório dos magistrados. Nesse sentindo, localizamos três pesquisas publicadas em revistas indexadas no Scielo.

A primeira pesquisa localizada foi publicada em 2004. O artigo analisa a atuação do STF no contexto do processo de abertura política e de consolidação da democracia (entre os anos de 1979 a 1999) e seu impacto nas demais dimensões sociais, a partir do estudo de percepção em dois veículos de imprensa (Folha de São Paulo e o Estado de São Paulo), tomados como parte da "opinião pública". Segundo a autora, foi possível inferir que o STF é percebido como um ator político no processo de redemocratização e consolidação da democracia, sendo que essa postura teve apoio na identidade profissional dos ministros e em seus conhecimentos técnicos para diferenciar-se dos outros poderes políticos (Oliveira, 2004).

Passados quatro anos, isto é, em 2008, foi publicado o estudo de Daniel Wei Liang Wang que, num diálogo entre direito e economia, busca estudar a escassez de recursos, os custos dos direitos e a cláusula de reserva do possível na jurisprudência do Supremo Tribunal Federal. O autor foca em decisões proferidas em temas como o direito à saúde, educação e intervenção federal pelo não pagamento de precatórios. O pesquisador observou incoerência e insuficiência de argumentação nos julgados estudados (Wang, 2008).

O último estudo localizado busca compreender como efetivamente é aplicado o princípio da igualdade nas decisões proferidas pelo STF e como a "análise de consequências" sociais e políticas pode ou não influir em suas decisões, levando em conta que a objetivação de critérios de avaliação da atuação da justiça e dos magistrados é essencial para o desenvolvimento da prestação jurisdicional (Rothenburg, 2009).

\section{Conclusão}

Foi possível perceber que alguns autores aparecem tanto nos encontros da ANPOCS, quanto nas publicações encontradas no Scielo, o que aponta para o foco dos seus trabalhos de pesquisa no tema. Os autores que foram encontrados em ambos os levantamentos são André Marenco dos Santos, Eduardo Meira Zauli, Fabiana Luci de Oliveira, Luciano Da Ros e Luiz Werneck Vianna.

Verificamos, ainda, que nenhum dos trabalhos localizados realiza pesquisa empírica utilizando técnicas de coletas de dados como entrevistas, etnografias ou observação participante. As pesquisas empíricas encontradas partem da análise documental, isto é, análise das decisões proferidas pelo Supremo Tribunal Federal tanto no sentido da construção de bancos de dados a partir das informações constantes nos processos quanto por meio do estudo de caso dos julgados do STF. Há também 
pesquisas que partem das bases de dados disponibilizadas pelo próprio Supremo e, ainda, pesquisas sobre as biografias dos ministros que partem de análise documental, tanto em revistas nas quais podem ser encontrados discursos por eles proferidos quanto no currículo dos magistrados disponíveis no site do STF. Apenas um trabalho também utiliza matérias jornalísticas para a elaboração da pesquisa.

Essa constatação aponta para a importância do desenvolvimento de investigações sobre a Corte Suprema brasileira, utilizando outras abordagens metodológicas e teóricas, como o Projeto ao qual nos vinculamos, "O Supremo por seus Ministros: a história oral do STF nos 25 anos da Constituição (1988-2013)", se propõe, isto é, a partir da realização de entrevistas com os ministros, reconstruindo suas trajetórias e não apenas por meio de análise documental. Isso porque, a base de dados que o projeto construirá, ficará disponível na página do CPDOC - Centro de Pesquisa e Documentação de História Contemporânea do Brasil - para consulta de quaisquer interessados e poderá fomentar a produção de uma ampla e variada gama de trabalhos acadêmicos.

Conforme dito no início de nosso trabalho, esse levantamento bibliográfico consiste em trabalho preliminar que será aprofundado. Nos próximos passos de nosso levantamento, focaremos em outros encontros anuais promovidos por organizações do campo das ciências sociais brasileiras, como aqueles promovidos pela Associação Brasileira de Ciência Política (ABCP) e a Sociedade Brasileira de Sociologia (SBS), assim como no mapeamento dos polos de produção do conhecimento que mais produzem sobre o Supremo Tribunal Federal, dentro dos programas de Pós Graduação nas Ciências Sociais, a partir do mapeamento dos autores que produziram sobre o tema e as escolas nas quais realizaram seus estudos de doutoramento.

\section{REFERÊNCIAS}

KANT DE LIMA, Roberto; MISSE, Michel; MENDES DE MIRANDA, Ana Paula. Violência, Criminalidade, Segurança Pública e Justiça Criminal no Brasil: Uma bibliografia. BIB, Rio de Janeiro, n. 50, 2000, p. 45 - 123.

OLIVEIRA, Fabiana Luci de (org.). Justiça em foco: Estudos Empíricos. Rio de Janeiro: Editora FGV, 2012.

SADEK, Maria Tereza Sadek. Estudos sobre o Sistema de Justiça. In: MICELI, Sérgio (org). O que ler na ciência social brasileira, vol. IV. São Paulo: Editora Sumaré, 2002.

VALLADARES, Licia do Prado; MEDEIROS, Lidia. Pensando as favelas do Rio de Janeiro: 1906-2000 uma bibiografia analítica. Rio de Janeiro: Relume Dumará; Rio de Janeiro: FAPERJ/URBANDATA, 2003. 
Fontes de Pesquisa

ABRAMO, Claudio Weber. Tempos de espera no Supremo Tribunal Federal. Revista Direito GV, São Paulo, v. 6, n. 2, p. 423-442, Dez. 2010.

ALMEIDA, Frederico de. As elites jurídicas e a política da administração da justiça no Brasil. In: Encontro Anual da ANPOCS, 33, 2009, Caxambu. Anais... São Paulo: ANPOCS, 2009.

ARAÚJO, Mateus Morais. Cortes constitucionais como veto players: O Supremo Tribunal Federal brasileiro e a teoria da absorção. In: Encontro Anual da ANPOCS, 35, 2011, Caxambu. Anais... São Paulo: ANPOCS, 2011.

BONAVIDES, Paulo. Jurisdição constitucional e legitimidade (algumas observações sobre o Brasil). Estudos Avançados, São Paulo, v. 18, n. 51, p. 127-150, Mai./Ago. 2004.

CARVALHO, Ernani Rodrigues de. Em busca da judicialização da política no Brasil: apontamentos para uma nova abordagem. Revista de Sociologia Política, Curitiba, n. 23, p. 127-139, Nov. 2004.

(2010). Trajetória da revisão judicial no desenho constitucional brasileiro: tutela, autonomia e judicialização. Sociologias, Porto Alegre, n. 23, p. 176-207, Jan./ Abr. 2010.

CHUEIRI, Vera Karam de; SAMPAIO, Joanna Maria de Araújo. Como levar o supremo tribunal federal a sério: sobre a suspensão de tutela antecipada n. 91 . Revista Direito GV, São Paulo, v. 5, n. 1, p. 45-66, Jan./Jun. 2009.

COSTA JÚNIOR, Alvaro Pereira Sampaio. O Judiciário e as agências reguladoras: a judicialização da política regulatória no Brasil sob a perspectiva do neoinstitucionalismo. In: Encontro Anual da Anpocs, 30, 2006, Caxambu. Anais... São Paulo: ANPOCS, 2006.

CUNHA FILHO, Marcio Camargo. Judiciário legislador? Análise da evolução da jurisprudência do Supremo Tribunal Federal no tratamento das omissões inconstitucionais. In: Encontro Anual da ANPOCS, 35, 2011, Caxambu. Anais... São Paulo: ANPOCS, 2011.

DA ROS, Luciano. Poder de Decreto e Accountability Horizontal: dinâmica institucional dos três poderes e medidas provisórias no Brasil pós-1988. Revista de Sociologia Política, Curitiba, v.16, n. 31, p. 143-160, Nov. 2008

DURAN-FERREIRA, Camila. O STF e a construção institucional das autoridades reguladoras do financeiro: um estudo de caso das ADINS. Revista Direito GV. São Paulo, v.5, n. 1, p. 67-94, Jan./Jun. 2009.

ELIAS DE OLIVEIRA, Vanessa. Judiciário e privatizações no Brasil: existe uma 
judicialização da política? Dados, Rio de Janeiro, v. 48, n. 3, p. 559-686, Jul./Set. 2005.

. (2009). Poder Judiciário: árbitro dos conflitos constitucionais entre estados e união. Lua Nova, São Paulo, n. 78, p. 223-250, 2009.

IORIO FILHO, Rafael Mario; SILVA, Fernanda Duarte Lopes Lucas. O Supremo Tribunal Federal e a Lei da Ficha Limpa: entre a técnica jurídica e a política. In: Encontro Anual da ANPOCS, 35, 2011, Caxambu. Anais... São Paulo: ANPOCS, 2011.

KOERNER, Andrei; BARATTO, Márcia; INATOMI, Celly Cook. Pensamento Jurídico e Decisão Judicial: o processo de controle concentrado em decisões do Supremo Tribunal Federal pós-1988. In: Encontro Anual da Anpocs, 31, 2007, Caxambu. Anais... São Paulo: ANPOCS, 2007.

LEWANDOWSKI, Andressa. Processos decisórios no Supremo Tribunal Federal. In: Encontro Anual da ANPOCS, 35, 2011, Caxambu. Anais... São Paulo: ANPOCS, 2011.

MARENCO DOS SANTOS, André; DA ROS, Luciano. Caminhos que levam à corte: carreiras e padrões de recrutamento dos ministros dos órgãos de cúpula do Judiciário. In: Encontro Anual da ANPOCS, 31, 2007, Caxambu. Anais... São Paulo: ANPOCS, 2007.

MARIANO SILVA, Jeferson. Elites de classe na judicialização da política? Associações empresariais e Ações Diretas de Inconstitucionalidade. In: Encontro Anual da Anpocs, 34, 2010, Caxambu. Anais... São Paulo: ANPOCS, 2010.

MARCHETTI, Vitor Emanuel Ferraz Júnior. O controle constitucional da atividade legislativa do executivo: Brasil e Argentina comparados. In: Encontro Anual da Anpocs, 27, 2003, Caxambu. Anais... São Paulo: ANPOCS, 2003.

OLIVEIRA, Fabiana Luci. A identidade profissional dos ministros do STF no processo de transição democrática no Brasil (1979/1999). In: Encontro Anual da Anpocs, 26, 2002, Caxambu. Anais... São Paulo: ANPOCS, 2002.

. (2004). O Supremo Tribunal Federal no processo de transição democrática: uma análise de conteúdo dos jornais Folha de s. Paulo e o Estado de S. Paulo. Revista de Sociologia e Política, Curitiba, n. 22, p. 101-118, Jun. 2004.

PACHECO, Cristina Carvalho. O Supremo Tribunal Federal e a Reforma do Estado do Governo Fernando Henrique Cardoso (1995-1998). In: Encontro Anual da Anpocs, 29, 2005, Caxambu. Anais... São Paulo: ANPOCS, 2005.

PORTO MACEDO JÚNIOR, Ronaldo; MARTES, Ana Cristina Braga. Reforma do Judiciário - debate e propostas. In: Encontro Anual da Anpocs, 24, 2000, Caxambu. Anais... São Paulo: ANPOCS, 2000. 
RIBEIRO, Leandro Molhano; PEIXOTO, Vitor Moraes; ARGUELHES, Diego. Processo decisório, Judiciário e Políticas Públicas. In: Encontro Anual da ANPOCS, 33, 2009, Caxambu. Anais... São Paulo: ANPOCS, 2009.

ROTHENBURG, Walter Claudius. O problema da igualdade real: comentário de algumas decisões do Supremo Tribunal Federal. Revista Direito GV, São Paulo, v. 5, n. 1, p. 107-124, Jan./Jun.2009

TAYLOR, Matthew M.; Da Ros, Luciano. Os partidos dentro e fora do poder: a judicialização como resultado contingente da estratégia política. Dados, Rio de Janeiro, v. 51, n. 4, p. 825-864, 2008.

VERBICARO, Loiane Prado. Um Estudo Sobre As Condições Facilitadoras Da Judicialização Da Política No Brasil. Revista Direito GV, São Paulo, v. 4, n. 2, p. 389406, Jul./Dez. 2008.

VERISSIMO, Marcos Paulo. A Constituição de 1988, vinte anos depois: suprema corte e ativismo judicial "à brasileira". Revista Direito $G V$, São Paulo, v. 4, n. 2, p. 407-440, Jul./Dez. 2008

VILHENA VIEIRA, Oscar. Supremocracia. Revista Direito GV, São Paulo, v. 4, n. 2, p. 441-463, Dez. 2008.

VOJVODIC, Adriana de Moraes; MACHADO, Ana Mara França; CARDOSO, Evorah Lusci Costa. Escrevendo um romance, primeiro capítulo: precedentes e processo decisório no STF. Revista Direito GV, São Paulo, v. 5, n. 1, p. 21-44, Jan./Jun.

WANG, Daniel Wei Liang. Escassez de recursos, custos dos direitos e reserva do possível na jurisprudência do STF. Revista Direito GV, São Paulo, v. 4, n. 2, p. 539568, Jul./Dez. 2008.

WERNECK VIANNA, Luiz. A judicialização da política e as relações entre os três poderes no Brasil (1988-1998). In: Encontro Anual da Anpocs, 23, 1999, Caxambu. Anais... São Paulo: ANPOCS, 1999.

WERNECK VIANNA, Luiz; BURGOS, Marcelo Baumann; SALLES, Paula Martins. Dezessete Anos de Judicialização Da Política. Tempo Social, São Paulo, v. 19, n. 2, p. 39-85, Nov. 2007.

XIMENES, Julia Maurmann. O Supremo Tribunal Federal e a cidadania à luz da influência comunitarista. Revista Direito GV, São Paulo, v. 6, n. 1, p. 119-141, Jun. 2010.

ZAULI, Eduardo Meira. Judicialização da política, Poder Judiciário e Comissões Parlamentares de Inquérito no Brasil. In: Encontro Anual da Anpocs, 34, 2010, Caxambu. Anais... São Paulo: ANPOCS, 2010.

. (2011). Judicialização da política, Poder Judiciário e Comissões Parlamentares de Inquérito no Brasil. Revista de Sociologia Política, v. 19, n. 40, 2011. 